\title{
The Dynamics of Inflammatory Markers in Patients with Suspected Acute Appendicitis
}

\author{
Ąžuolas Algimantas Kaminskas ${ }^{1}{ }^{(0)}$, Raminta Lukšaitè-Lukštè ${ }^{2, * \mathbb{D}}$, Eugenijus Jasiūnas ${ }^{3}$, Artūras Samuilis ${ }^{2}$, \\ Vytautas Augustinavičius ${ }^{2}$, Marius Kryžauskas ${ }^{4}$, Kęstutis Strupas ${ }^{4}$ and Tomas Poškus ${ }^{4}$ (D) \\ 1 Faculty of Medicine, Vilnius University, LT-03101 Vilnius, Lithuania; azuolas.kaminskas@gmail.com \\ 2 Department of Radiology, Nuclear Medicine and Medical Physics, Institute of Biomedical Sciences, \\ Faculty of Medicine, Vilnius University, LT-08661 Vilnius, Lithuania; arturas.samuilis@santa.lt (A.S.); \\ Vytautas.Augustinavicius@santa.lt (V.A.) \\ 3 Center of Informatics and Development, Vilnius University Hospital Santaros Klinikos, \\ LT-08661 Vilnius, Lithuania; Eugenijus.Jasiunas@santa.lt \\ 4 Clinic of Gastroenterology, Nephro-Urology, and Surgery, Institute of Clinical Medicine, Faculty of Medicine, \\ Vilnius University, LT-08661 Vilnius, Lithuania; marius.kryzauskas@santa.lt (M.K.); \\ kestutis.strupas@santa.lt (K.S.); Tomas.Poskus@santa.lt (T.P.) \\ * Correspondence: raminta.luksaite@santa.lt; Tel.: +37-068-9606-11
}

check for updates

Citation: Kaminskas, A.A.; Lukšaitè-Lukštè, R.; Jasiūnas, E.; Samuilis, A.; Augustinavičius, V.; Kryžauskas, M.; Strupas, K.; Poškus, T. The Dynamics of Inflammatory Markers in Patients with Suspected Acute Appendicitis. Medicina 2021, 57, 1384. https://doi.org/10.3390/ medicina57121384

Academic Editor: Rinaldo Pellicano

Received: 16 November 2021 Accepted: 15 December 2021 Published: 20 December 2021

Publisher's Note: MDPI stays neutral with regard to jurisdictional claims in published maps and institutional affiliations.

Copyright: (c) 2021 by the authors. Licensee MDPI, Basel, Switzerland. This article is an open access article distributed under the terms and conditions of the Creative Commons Attribution (CC BY) license (https:/ / creativecommons.org/licenses/by/ $4.0 /)$.
Abstract: Background: Laboratory tests of inflammatory mediators are routinely used in the diagnosis of acute appendicitis (AA). The aim of this study was to evaluate the differences of dynamics of inflammatory markers of the blood in patients with suspected acute appendicitis between complicated AA (CAA), non-complicated AA (NAA), and when AA was excluded (No-AA). Methods: This was a retrospective analysis of prospectively collected data of patients presented to the Emergency Department (ER) of a tertiary hospital center during a three-year period. All patients suspected of acute appendicitis were prospectively registered from 1 January 2016 to 31 December 2018. The dynamics of inflammatory markers of the blood between different types of AA (No-AA, NAA or CAA) during different periods of time are presented. Results: A total of 453 patients were included in the study, with 297 patients in the No-AA group, 99 in the NAA group, and 57 in the CAA group. White blood cell (WBC) count in the No-AA decreased with time, with a statistically significant difference between the $<8 \mathrm{~h}$ and $25-72 \mathrm{~h}$ group. The neutrophils (NEU) percentage decreased in the No-AA group and was statistically significantly different between the $<8 \mathrm{~h}$ and $25-72 \mathrm{~h}$ and $<8 \mathrm{~h}$ and $>72 \mathrm{~h}$ groups. C-reactive protein (CRP) increased significantly in the No-AA group throughout all time intervals, and from the first $24 \mathrm{~h}$ to the $25-72 \mathrm{~h}$ in the NAA and CAA groups. There was a statistically significant difference between the WBC count between No-AA, NAA, and No-AA and CAA groups during the first 24 and $24-48 \mathrm{~h}$. There was a statistically significant difference between NEU percentage and LYMP percentage and in the NEU/LYMP ratio between No-AA and CAA groups through all time periods. CRP was significantly higher in the first $24 \mathrm{~h}$ in the CAA than in the No-AA group, and in the $24-48 \mathrm{~h}$ in the CAA group than in the No-AA and NAA groups. The linear logistic regression model, involving inflammatory mediators and clinical characteristics, showed mediocre diagnostic accuracy for diagnosing AA with an AUC of 0.737 (0.671-0.802). Conclusions: Increasing concentrations of inflammatory markers are more characteristic in CAA patients than in No-AA during the first $48 \mathrm{~h}$ after onset of the disease. A combination of laboratory tests with clinical signs and symptoms has a mediocre diagnostic accuracy in suspecting AA.

Keywords: acute appendicitis; laboratory tests; inflammatory markers; complicated acute appendicitis; non-complicated acute appendicitis

\section{Introduction}

Acute appendicitis (AA) is one of the most common causes of acute abdomen in adults, with 17.7 million cases worldwide in 2019 and an incidence of 228 cases per 
100,000 population [1,2]. Early diagnosis of AA, and proper identification of the type of AA, are crucial to achieve optimal treatment results. Strategies for complicated (CAA) and non-complicated (NAA) AA treatments differ [3]. If CAA is not diagnosed and treated early, serious complications can develop; on the other hand, NAA can be treated conservatively [3-5]. Clinical and laboratory scores can be used to rule out the diagnosis of appendicitis $[3,6]$. However, AA remains diagnostically challenging, as the negative appendectomy (NA) incidence can reach up to 10-30\% [7-10].

The clinical diagnosis is confirmed and the specific type of AA (CAA or NAA) is diagnosed with imaging studies, such as transabdominal ultrasound (TUS) and computed tomography (CT) scan, or MRI scan in pregnant women [11]. Their use has been associated with reduced NA rates [12,13]. Nonetheless, TUS is a subjective diagnostic tool with its middling sensitivity and specificity (about $77 \%$ and $60 \%$, respectively), as well as the limited ability to visualize the appendix (normal appendix is detected in $71 \%$ of cases) $[14,15]$. CT has high sensitivity and specificity (about $90-95 \%$ and $94 \%$, respectively) in visualizing AA, however, it uses ionizing radiation and is associated with an increased risk of future oncological diseases, especially in young patients [16-18]. Conditional use of CT scanning after US could be a possible solution for this problem [19].

Another possible tool that could be used to suspect, diagnose, or even differentiate AA types is laboratory tests. Some studies have shown a possible correlation between an elevated concentration of inflammatory markers of the blood and the diagnosis of AA [20]. On the other hand, the absence of inflammatory changes in the blood cannot exclude the diagnosis of AA [21,22]. Furthermore, the literature suggests that inflammatory changes in the blood could be used to diagnose a specific type of AA (CAA or NAA) [23]. However, there are limited data in the literature on the use of laboratory tests in the diagnosis of AA compared to the number of studies performed on imaging examinations. The aim of this study was to evaluate the differences in the dynamics of inflammatory markers of the blood in patients with suspected acute appendicitis between complicated AA (CAA), non-complicated AA (NAA), and when AA was excluded (No-AA).

\section{Materials and Methods}

This is a pre-planned analysis of inflammatory markers' data, which were obtained from a cohort of patients from our previous research [19]. In short, all patients suspected of acute appendicitis were prospectively registered from 1 January 2016 to 31 December 2018. All patients over 18 years of age who were admitted to the emergency department because of symptoms suggestive of AA and consulted by a general surgeon were enrolled into the database. Only pregnant women were excluded from the database. All patients from the database underwent transabdominal ultrasound (TUS) and CT scan later if TUS was inconclusive and clinical suspicion of AA was still present. The TUS criteria for probable radiological diagnosis of AA were a diameter of appendix at $\sim 7 \mathrm{~mm}$ (or less), wall thickness of the appendix at $\sim 2 \mathrm{~mm}$ (or less), compressible/partially compressible appendix with or without secondary findings of free fluid in right iliac fossa, lymphadenopathy, and infiltration of surrounding tissue. The $\mathrm{CT}$ scan criteria for radiological diagnosis of AA were diameter of appendix $\geq 7 \mathrm{~mm}$ and wall thickness of the appendix $\geq 2 \mathrm{~mm}$, with possible secondary signs of free fluid in right iliac fossa, lymphadenopathy, and fat stranding. Patients who underwent both CT and US to rule out AA were included in the study. The following information was collected and analysed in this study: white blood cell count (WBC), percentage of neutrophils (NEU), percentage of lymphocytes (LYMP), percentage of monocytes (MON), percentage of eosinophils (EOS), percentage of basophils (BAS), and concentration of C-reactive protein (CRP). All patients included in this study were divided into three groups based on their final diagnosis: complicated acute appendicitis (CAA) group, non-complicated acute appendicitis (NAA) group, and no appendicitis (No-AA) group. The final diagnosis of each patient was determined by a panel of experts based on histopathology, imaging, surgical findings, and clinical information.

The histological criteria for diagnosing AA were the following: 
- Catarrhal appendicitis—neutrophils within mucosa and mucosal ulceration, with or without intraluminal neutrophils;

- Secondary changes/periappendicitis-inflammation of serosa and subserosa, infiltration extends no further than outer muscularis propria;

- Phlegmonous appendicitis-neutrophilic infiltration of mucosa, submucosa, and muscularis propria; transmural inflammation; extensive ulceration and intramural abscesses; vascular thrombosis;

- Gangrenous appendicitis—transmural inflammation with areas of necrosis, extensive mucosal ulceration.

The surgical findings for suspecting AA were the following:

- Catarrhal appendicitis-no visible changes;

- Secondary changes/periappendicitis-may appear normal or serosa may be dull, congested, and show exudate;

- Phlegmonous appendicitis_-dilated or increased diameter appendix; dull serosa; dilatation and congestion of surface vessels; fibrinopurulent serosal exudate;

- Gangrenous appendicitis_appendiceal wall friable; purple, green, or black.

We did not define specific clinical criteria for the diagnosis of acute appendicitis (i.e., we suspected AA based on classical clinical signs and symptoms).

Only those patients who showed signs of AA in the CT scan were operated on, with a few exceptional cases when patients underwent surgery without visible signs of AA in CT scan. In addition, some CAA patients also did not have surgery-they underwent percutaneous drainage and conservative treatment.

The dynamics of inflammatory markers of the blood were evaluated at different time intervals: I (less than $8 \mathrm{~h}$ from the onset of the disease), II (8-16 h after the onset of the disease), III (17-24 h), IV (25-72 h), and V (more than $72 \mathrm{~h}$ after the beginning of the illness).

\section{Statistical Analysis}

R statistical software package Version 4.0.5 (C) The R Foundation for Statistical Computing, Vienna, Austria), Rstudio Version 1.2.5042 ( ) 2009-2021 RStudio, Inc., Boston, MA, USA), IBM SPSS Statistics V.23, and G*Power V. 3.1.9.4 Universität Düsseldorf, Germany were used for data analysis. Interval and ratio variables were described as medians, first (Q1) and third (Q3) quartiles, and interquartile range (IQR 75\%). Shapiro-Wilk and Anderson-Darling tests were used to check the normality of the data. Nominal variables were described by their repeatability and percentage of the corresponding subgroup of the sample. Nonparametric Kruskal-Wallis H test was used to evaluate the dependence of several independent interval or rank variable samples. Epsilon squared $\left(\varepsilon^{2}\right)$ was used to measure the effect size (when $\varepsilon^{2}$ is considered: 0.00-0.01-negligible effect size, $0.01-0.04-$ weak effect size, 0.04-0.16-moderate effect size, 0.16-0.36-relatively strong effect size, 0.36-0.64—strong effect size, 0.64-1.00—-very strong effect size; according to Rea and Parker (1992)). Dunn's test was used to determine statistically significant relationships between pairs of variables. To determine the dependence and its strength between nominal and categorical variables, the Chi-squared test and Cramér's V $\left(\varphi_{\mathrm{c}}\right)$ (when data are described in $\mathrm{n} \times \mathrm{k}$ type tables) effect sizes with their associated $p$ values were used. According to Cohen (1988) (Table 1):

Table 1. The guidelines according to Cohen (1988).

\begin{tabular}{lllll}
\hline Df & Negligible & Small & Medium & Large \\
\hline 1 & $0-0.1$ & $0.1-0.3$ & $0.3-0.5$ & 0.5 or more \\
2 & $0-0.07$ & $0.07-0.21$ & $0.21-0.35$ & 0.35 or more \\
3 & $0-0.06$ & $0.06-0.17$ & $0.17-0.29$ & 0.29 or more \\
4 & $0-0.05$ & $0.05-0.15$ & $0.15-0.25$ & 0.25 or more \\
5 & $0-0.05$ & $0.05-0.13$ & $0.13-0.22$ & 0.22 or more \\
\hline
\end{tabular}

Df *-Degrees of freedom (number of variables-1). 
The Youden criterion was used for determining the optimal cut points for values of the laboratory indicators. A prognostic model was developed by using multivariate logistic regression. The pseudo-coefficient of determination was calculated by using more liberal Cragg-Uhler and more rigorous McFadden methods (McFadden's pseudo $\mathrm{R}^{2}$ ranging from 0.2 to 0.4 indicates a very good model fit). In addition to pseudo-coefficient of determination, sensitivity, specificity, positive and negative predictive values, and area under the curve (AUC or AUROC) were provided for model accuracy assessment. The classification ability of the model was considered good when AUROC was $>0.7$ but $<0.8$, and AUROC $>0.8$ was considered as excellent classification ability of the model. To test the hypotheses, we selected the significance of statistical tests $\alpha=0.05$ ( $p$ value $<0.05$ ) and the power of statistical tests $1-\beta=0.95$.

\section{Results}

Out of the 1855 patients in the database, 453 patients were included in the study, with 297 patients in the No-AA group, 99 in the NAA group, and 57 in the CAA group. Their clinical and demographic characteristics are presented in Table 2.

\subsection{Dynamics of Inflammatory Markers within No-AA, NAA, and CAA Groups}

Figure $1 \mathrm{~A}-\mathrm{C}$ show the overall dynamics of laboratory tests in three study groups at five different time intervals.

Statistically significant differences between different time periods within the groups and their values are presented (Table 3 ).

The WBC count in the No-AA group is decreasing with time, with a statistically significant difference between $<8 \mathrm{~h}$ and $25-72 \mathrm{~h}$ group ( $p$ value $<0.05$ ). The WBC count is not statistically significantly different in other groups and time periods. NEU percentage decreases in the No-AA group and is statistically significantly different between the $<8 \mathrm{~h}$ and $25-72 \mathrm{~h}$ and $<8 \mathrm{~h}$ and $>72 \mathrm{~h}$ groups. No significant differences are observed between LYMP percentage and NEU/LYMP ratios between the groups. CRP increases significantly in the No-AA group throughout all time intervals, and from the first $24 \mathrm{~h}$ to the $25-72 \mathrm{~h}$ in the NAA and CAA groups.

\subsection{Comparison of Inflammatory Markers Dynamics between No-AA, NAA, and CAA Groups}

Figure $2 \mathrm{~A}-\mathrm{C}$ present the comparison of the groups by levels of inflammatory markers during different time periods.

There is a statistically significant difference between the WBC count between No-AA, NAA, and No-AA and CAA groups during the first 24 and $24-48 \mathrm{~h}$. There is a statistically significant difference between NEU percentage and LYMP percentage and in the NEU/LYMP ratio between No-AA and CAA groups through all time periods. CRP is significantly higher in the first $24 \mathrm{~h}$ in the CAA than in the No-AA group, and in the 24-48 $\mathrm{h}$ in the CAA group than in the No-AA and NAA groups. 
Table 2. Demographic and clinical characteristics of patients according to three main time intervals from the onset of the disease.

\begin{tabular}{|c|c|c|c|c|c|c|c|c|c|}
\hline \multicolumn{10}{|c|}{ Overall $(n=453)$} \\
\hline Type of Disease & \multicolumn{3}{|c|}{ No-AA $(n=297)$} & \multicolumn{3}{|c|}{ NAA $(n=99)$} & \multicolumn{3}{|c|}{ CAA $(n=57)$} \\
\hline Time of disease (hours) & $\leq 24 \mathrm{~h}$ & $25-48 \mathrm{~h}$ & $>48 \mathrm{~h}$ & $\leq 24 \mathrm{~h}$ & $25-48 \mathrm{~h}$ & $>48 \mathrm{~h}$ & $\leq 24 \mathrm{~h}$ & $25-48 \mathrm{~h}$ & $>48 \mathrm{~h}$ \\
\hline Age (years) & $28(18-91)$ & $38(19-85)$ & $40(18-89)$ & $30(18-72)$ & $31(22-76)$ & $32(21-39)$ & $48(19-83)$ & $49(21-78)$ & $48(23-77)$ \\
\hline \multicolumn{10}{|l|}{ Laboratory tests: } \\
\hline WBC $\left({ }^{*} 10 \mathrm{e} 9 / \mathrm{L}\right)$ & $11(3-26)$ & $10(3-22)$ & $10(4-20)$ & $13(6-24)$ & $12(3-18)$ & $11(8-15)$ & $14(7-21)$ & $16(5-24)$ & $13(5-21)$ \\
\hline NEU $(\%)$ & $78(45-96)$ & $76(45-94)$ & $73(30-90)$ & $80(51-93)$ & $79(64-94)$ & $78(68-90)$ & 85 (60-97) & $82(66-87)$ & $81(68-89)$ \\
\hline LYMP (\%) & $14(2-47)$ & $15(3-64)$ & $17(4-63)$ & $13(2-36)$ & $11(4-24)$ & $15(6-21)$ & $8(2-23)$ & $9(4-24)$ & $10(4-24)$ \\
\hline NEU/LYMP & $6(0-43)$ & $5(1-29)$ & $4(0-24)$ & $6(1-40)$ & $7(3-24)$ & $5(3-16)$ & $10(3-46)$ & $9(3-23)$ & $8(3-23)$ \\
\hline $\mathrm{CRP}(\mathrm{mg} / \mathrm{L})$ & $12(0-185)$ & $50(0-228)$ & $58(0-358)$ & $13(0-260)$ & $47(0-230)$ & $22(9-210)$ & $47(1-212)$ & $124(20-371)$ & $80(13-284)$ \\
\hline
\end{tabular}

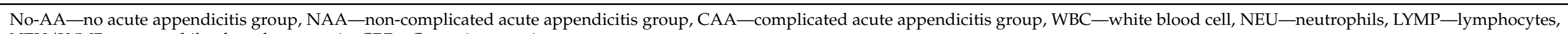

NEU/LYMP—neutrophil to lymphocyte ratio, CRP—C-reactive protein.

Table 3. Statistically significant differences between different time periods within the groups and their values.

\begin{tabular}{|c|c|c|c|c|c|}
\hline Group & Parameter & Time Period (1) & Time Period (2) & $p$-Value & Adjusted $p$-Value \\
\hline \multirow{9}{*}{ No-AA } & WBC $\left({ }^{*} 10 \mathrm{e} 9 / \mathrm{L}\right)$ & $<8 \mathrm{~h}$ & $25-72 \mathrm{~h}$ & 0 & 0.01 \\
\hline & \multirow{2}{*}{ NEU $(\%)$} & $<8 \mathrm{~h}$ & $25-72 \mathrm{~h}$ & 0 & 0.03 \\
\hline & & $<8 \mathrm{~h}$ & $>72 \mathrm{~h}$ & 0 & 0.02 \\
\hline & LYMP (\%) & \multicolumn{4}{|c|}{ No statistically significant differences between time intervals } \\
\hline & NEU/LYMP & \multicolumn{4}{|c|}{ No statistically significant differences between time intervals } \\
\hline & \multirow{4}{*}{$\mathrm{CRP}(\mathrm{mg} / \mathrm{L})$} & $<8 \mathrm{~h}$ & $17-24 \mathrm{~h}$ & 0 & 0.05 \\
\hline & & $<8 \mathrm{~h}$ & $>72 \mathrm{~h}$ & 0 & 0 \\
\hline & & $8-16 \mathrm{~h}$ & $25-72 \mathrm{~h}$ & 0 & 0 \\
\hline & & $8-16 \mathrm{~h}$ & $>72 \mathrm{~h}$ & 0 & 0 \\
\hline
\end{tabular}


Table 3. Cont

\begin{tabular}{|c|c|c|c|c|c|}
\hline Group & Parameter & Time Period (1) & Time Period (2) & $p$-Value & Adjusted $p$-Value \\
\hline \multirow{5}{*}{ NAA } & WBC $\left({ }^{*} 10 \mathrm{e} 9 / \mathrm{L}\right)$ & \multicolumn{4}{|c|}{ No statistically significant differences between time intervals } \\
\hline & NEU $(\%)$ & \multicolumn{4}{|c|}{ No statistically significant differences between time intervals } \\
\hline & NEU/LYMP & \multicolumn{4}{|c|}{ No statistically significant differences between time intervals } \\
\hline & \multirow[b]{2}{*}{$\mathrm{CRP}(\mathrm{mg} / \mathrm{L})$} & $<8 \mathrm{~h}$ & $25-72 \mathrm{~h}$ & 0 & 0.04 \\
\hline & & $8-16 \mathrm{~h}$ & $17-24 \mathrm{~h}$ & 0 & 0 \\
\hline \multirow{6}{*}{ CAA } & WBC $(* 10 \mathrm{e} 9 / \mathrm{L})$ & \multicolumn{4}{|c|}{ No statistically significant differences between time intervals } \\
\hline & NEU $(\%)$ & \multicolumn{4}{|c|}{ No statistically significant differences between time intervals } \\
\hline & LYMP (\%) & \multicolumn{4}{|c|}{ No statistically significant differences between time intervals } \\
\hline & NEU/LYMP & \multicolumn{4}{|c|}{ No statistically significant differences between time intervals } \\
\hline & \multirow{2}{*}{$\mathrm{CRP}(\mathrm{mg} / \mathrm{L})$} & $<8 \mathrm{~h}$ & $25-72 \mathrm{~h}$ & 0 & 0.01 \\
\hline & & $8-16 \mathrm{~h}$ & $25-72 \mathrm{~h}$ & 0 & 0.02 \\
\hline
\end{tabular}

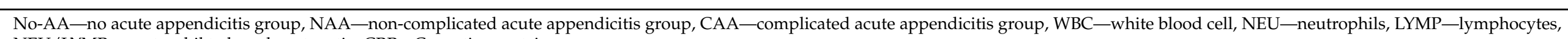
NEU/LYMP—neutrophil to lymphocyte ratio, CRP—C-reactive protein. 


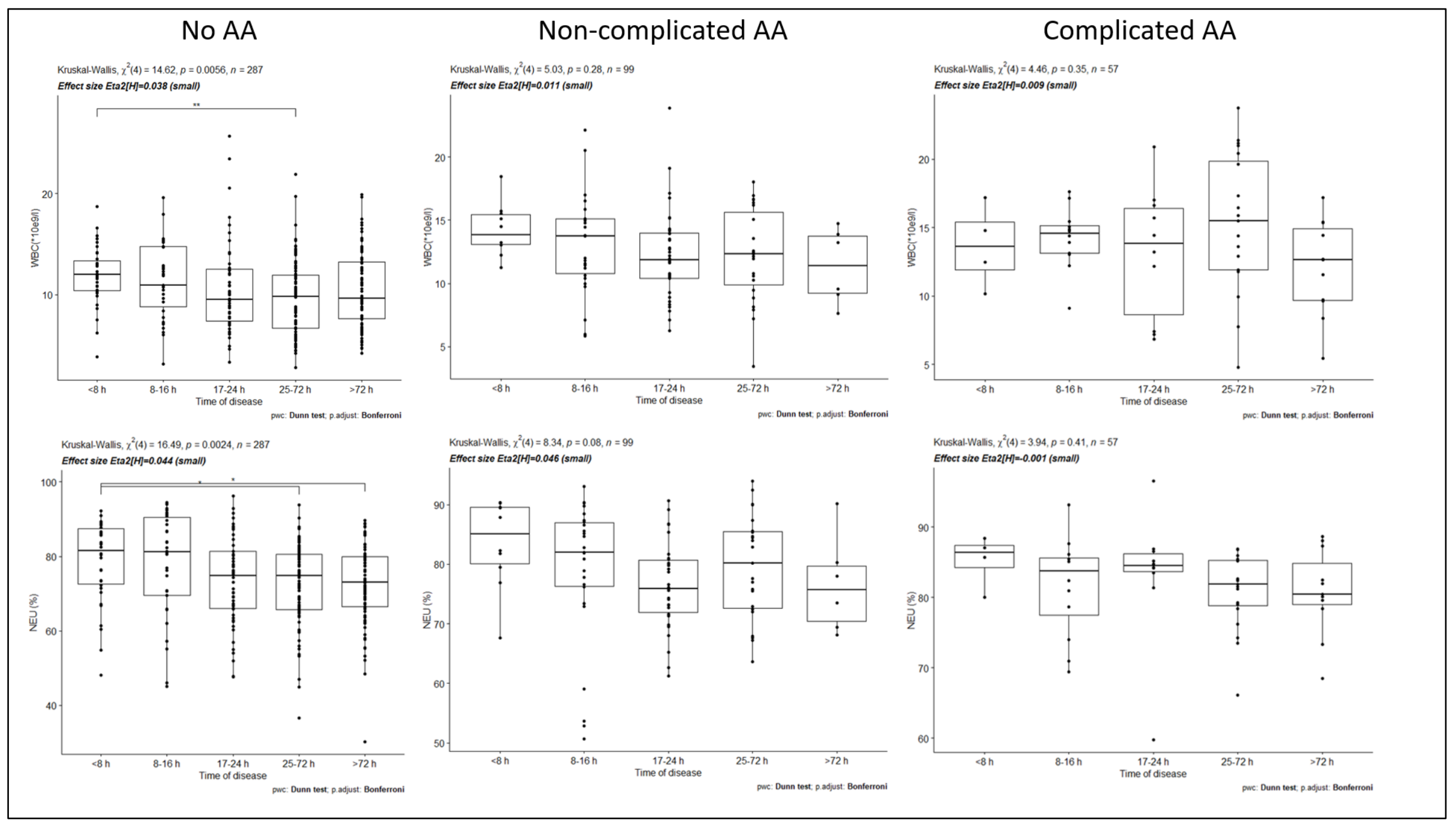

(A)

Figure 1. Cont. 


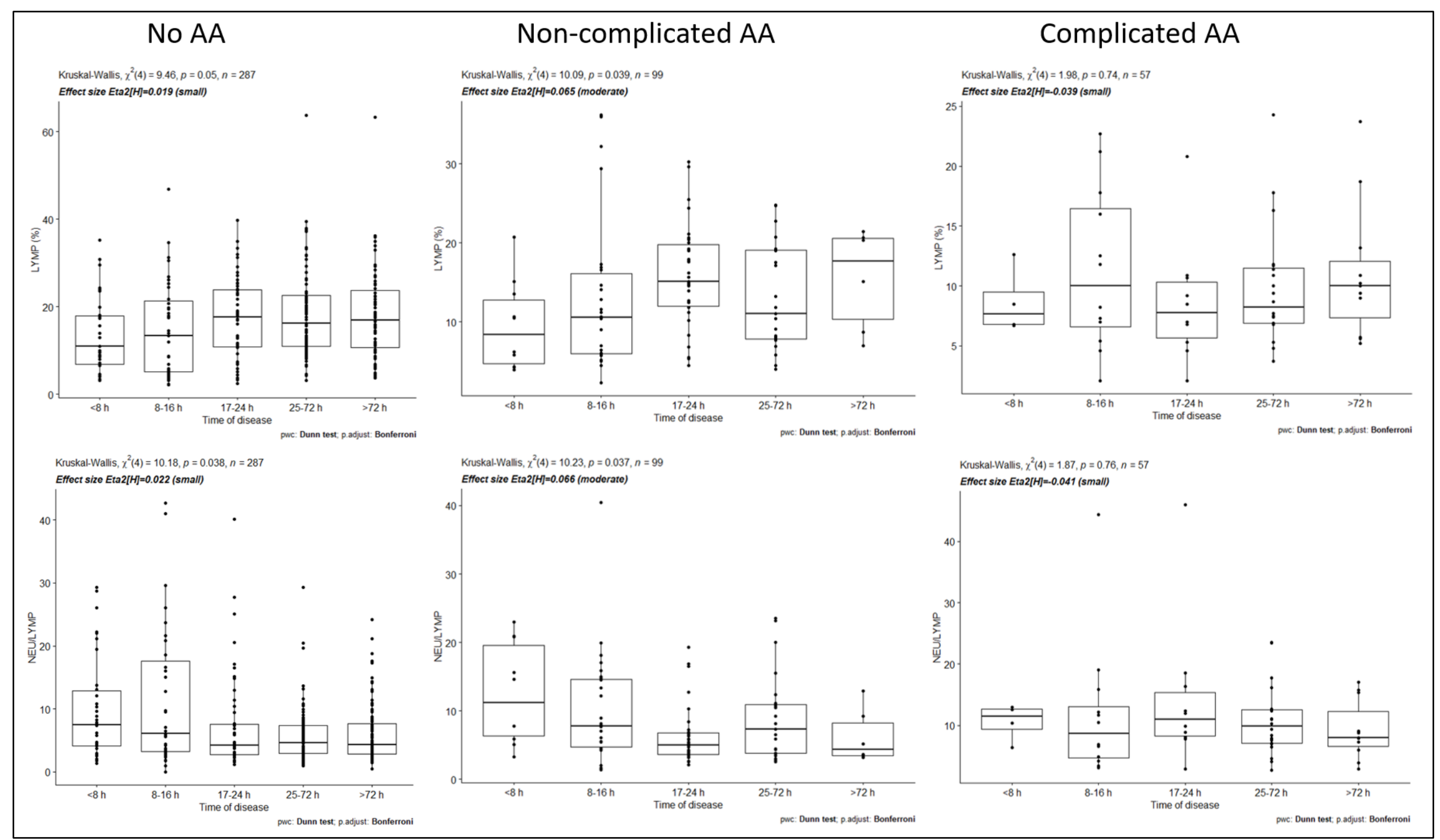

(B)

Figure 1. Cont. 

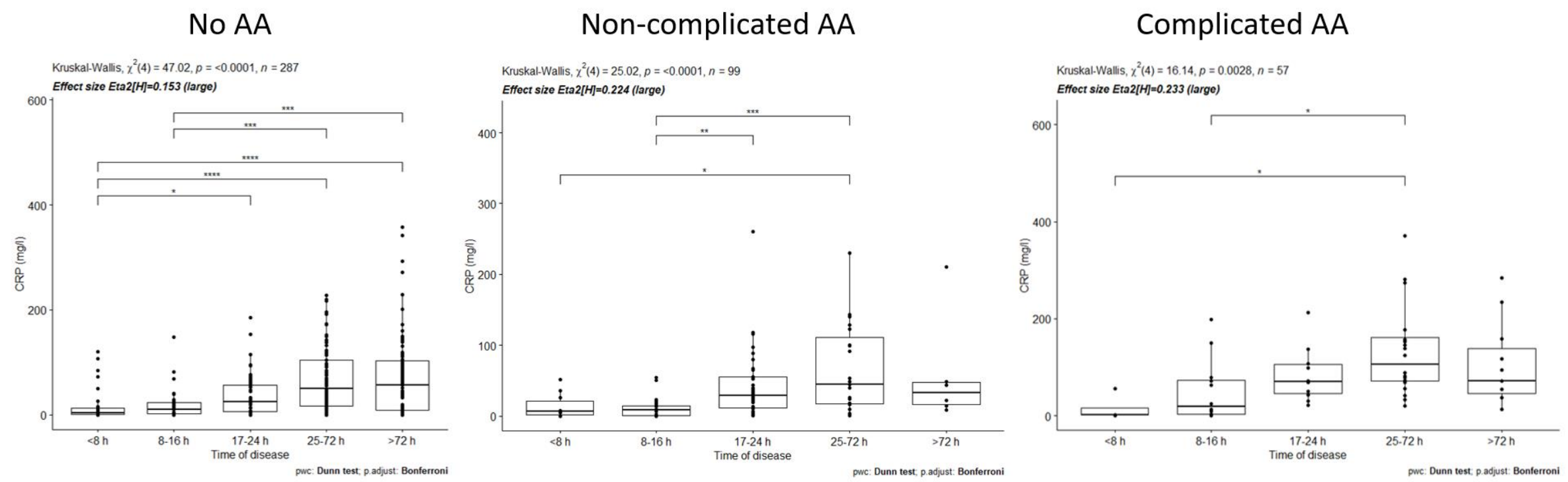

(C)

Figure 1. (A). No-AA—no acute appendicitis group, NAA—non-complicated acute appendicitis group, CAA—complicated acute appendicitis group, WBC-white blood cell, NEU—neutrophils. (B). No-AA—no acute appendicitis group, NAA—non-complicated acute appendicitis group, CAA—complicated acute appendicitis group, LYMP—lymphocytes, NEU/LYMP—neutrophil to lymphocyte ratio. (C). No-AA—no acute appendicitis group, NAA—non-complicated acute appendicitis group, CAA—complicated acute appendicitis group, CRP-C-reactive protein. ${ }^{*} * *, * * *$ and ${ }^{* * * *}$-indicates statistically significant differences between groups. 


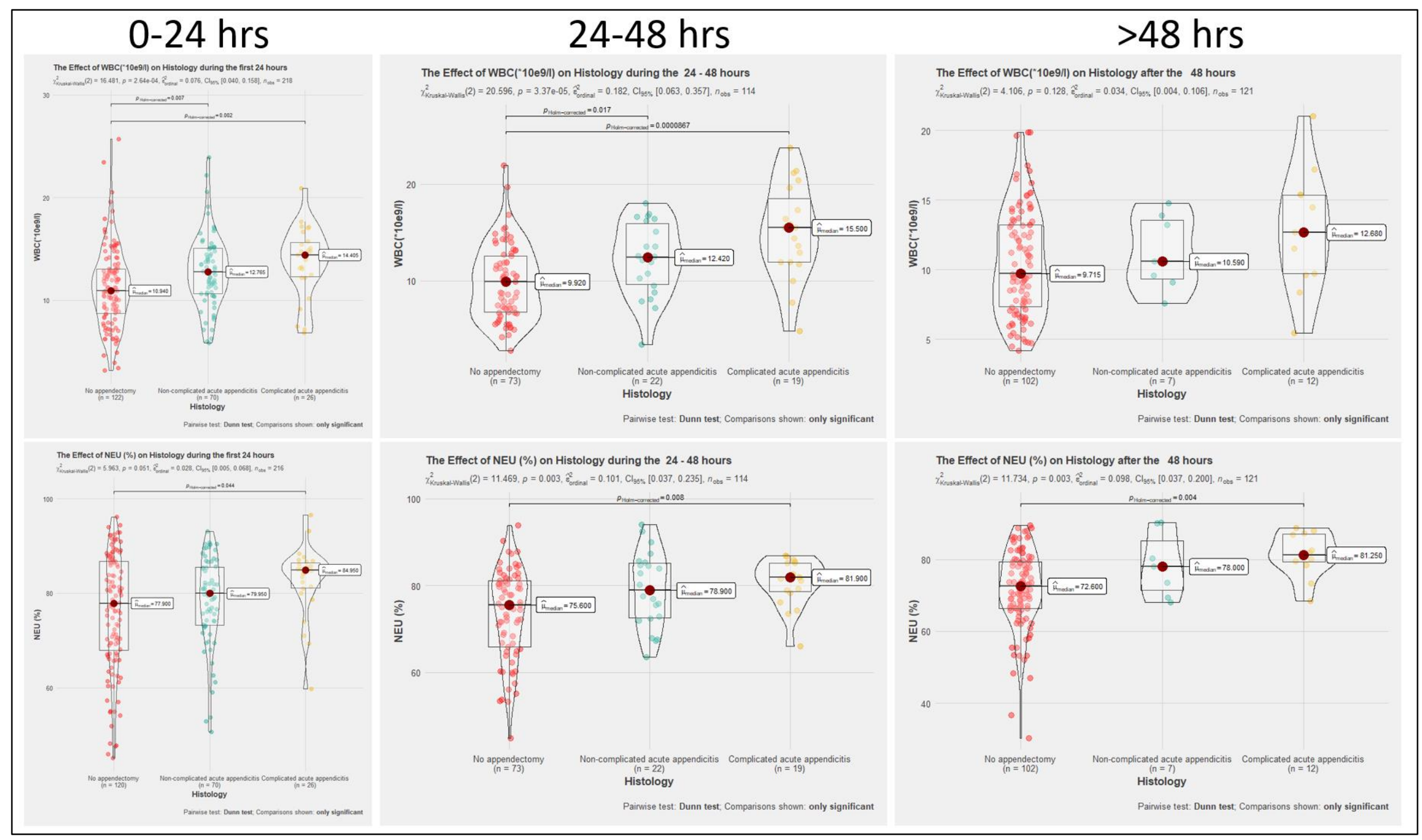

(A)

Figure 2. Cont. 


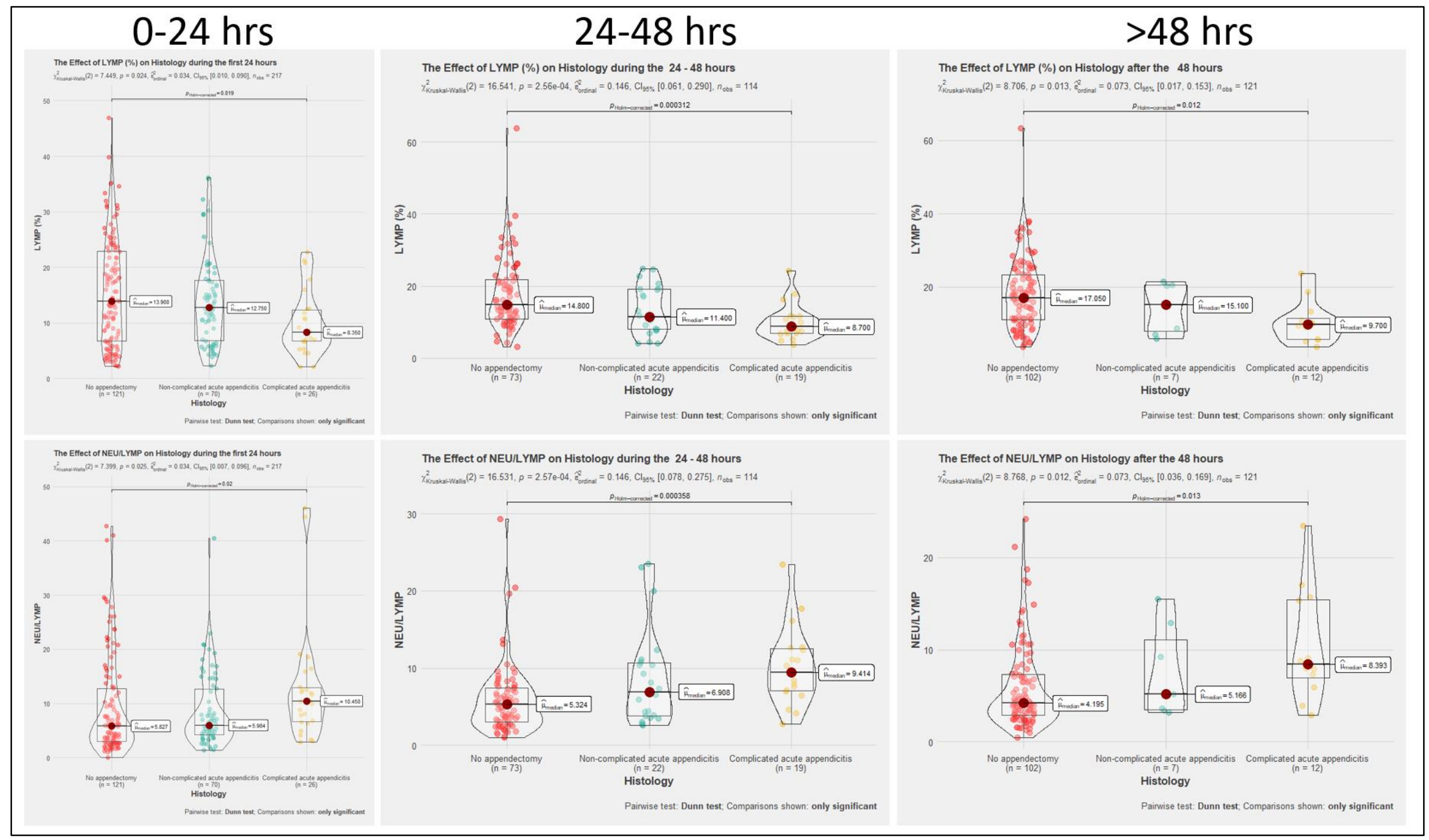

(B)

Figure 2. Cont. 


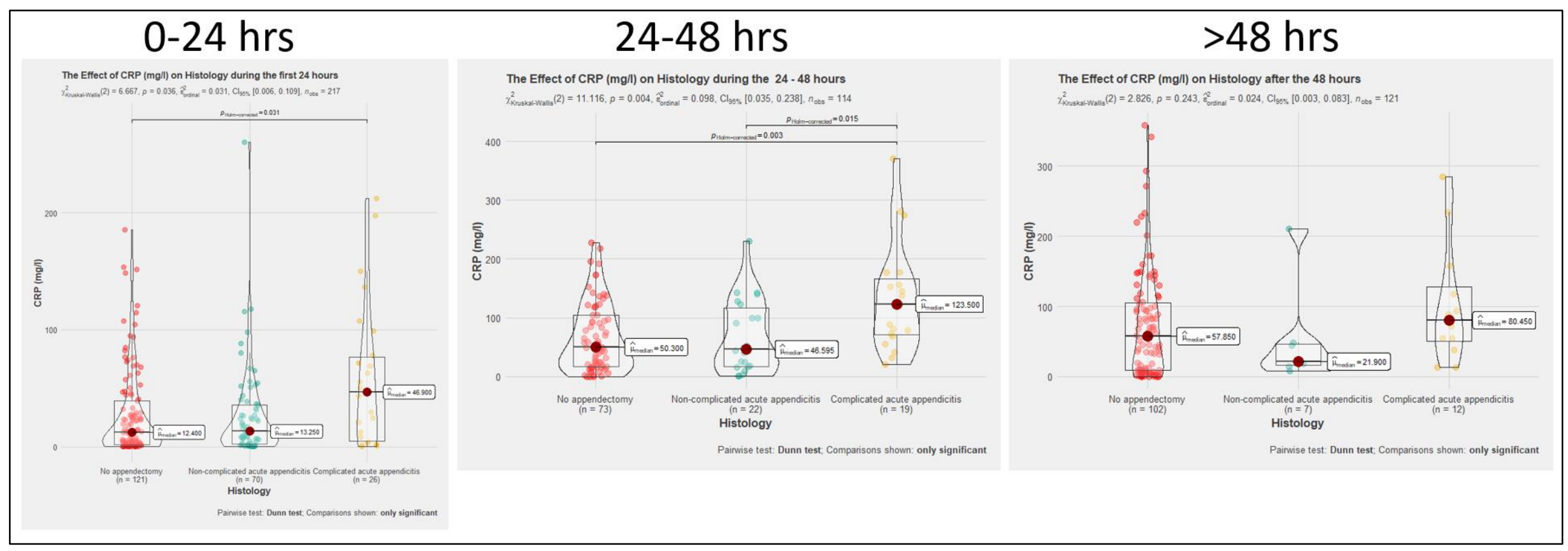

(C)

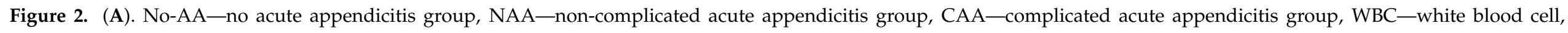

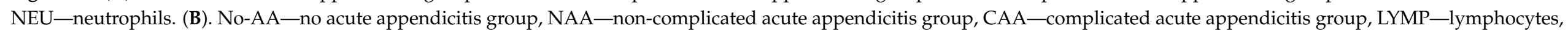

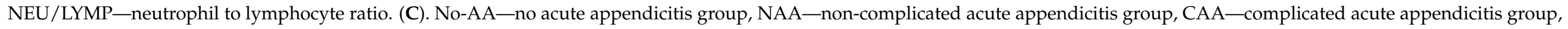
$\mathrm{CRP}-\mathrm{C}$-reactive protein. 


\subsection{Linear Logistic Regression Model on Inflammatory Markers and the Diagnosis of AA}

A linear logistic regression model was created to differentiate between combined AA groups and the No-AA group (Figure 3). The AUC of the model for diagnosing acute appendicitis is $0.737(0.671-0.802)$.

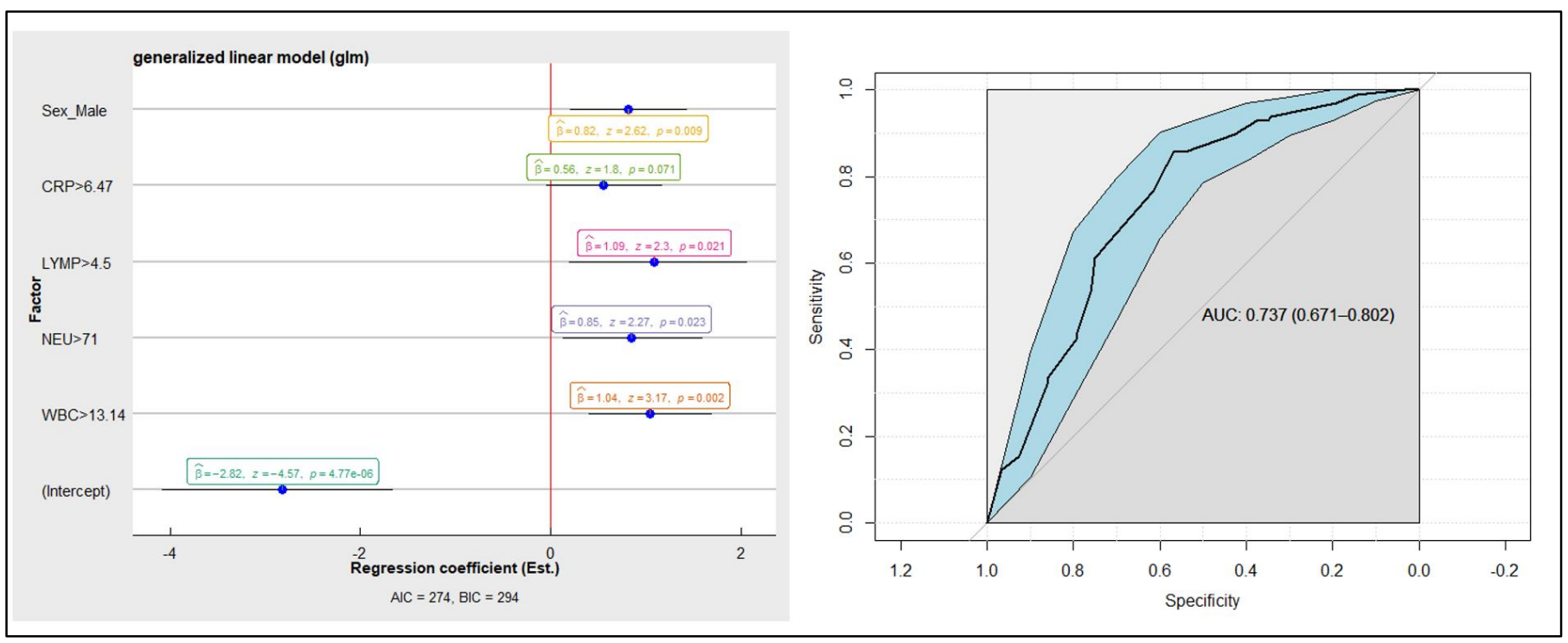

Figure 3. Linear logistic regression model with area under the curve (AUC) presented graphically.

\section{Discussion}

We found that some inflammatory markers differ within groups of patients, with varied duration from the onset of symptoms. The biggest changes were seen with the increase in the CRP concentration in all groups and the decrease in the WBC count and the NEU in the NAA group.

We also found that WBC levels are higher in both NAA and CAA groups than in the No-AA group within the first $48 \mathrm{~h}$. The NEU percentage and the NEU/LYMP ratio are higher in the CAA than in the No-AA group and, respectively, the LYMP percentage is higher in the No-AA group than in the CAA group, despite the duration of the disease. CRP is higher in the CAA than in the No-AA group within the first $24 \mathrm{~h}$, and higher than in both the No-AA and NAA groups within $24-48 \mathrm{~h}$.

The diagnostic model, involving only inflammatory mediators and clinical characteristics, can accurately diagnose AA in $73 \%$ of cases.

This is a prospective real-world cohort study, where all the patients with suspected AA were included and followed up to one month after their initial visit to confirm the diagnosis. However, the study has several drawbacks. All data were collected at the single tertiary center, so the results may differ from situations in other treatment facilities. All blood samples were taken and analysed according to the usual hospital procedures, in the absence of a specific study protocol defining how samples should be taken, transported, and analysed. Furthermore, in this study, we only analysed the dynamics of inflammatory markers between different patients in different groups, however, we did not analyse the changes in inflammatory markers in the same patients, as could be performed in patients under observation.

This study confirms the results of previous research, where the diagnostic accuracy of inflammatory mediators reaches $75 \%[7,24-26]$. The addition of a conditional CT protocol in this group of patients resulted in a diagnostic accuracy of $96 \%$ and the overall use of CT of $29 \%$ for diagnosis [19]. This is very similar to other series, where the use of CT scans resulted in high diagnostic effectiveness $[12,16,17,27-30]$. 
Nevertheless, as suspicion of AA is common in young adults, the increased future cancer risk is an important consideration. There is a need for non-radioactive, repeatable diagnostic tools for AA, and inflammatory markers are one of them. One of the main areas where laboratory tests could be very useful is a triage of the patients and referral to imaging examinations. A prospective observational study was performed to evaluate the accuracy of a diagnostic panel of laboratory tests which consisted of WBC, CRP, and myeloid related protein 8/14 (MRP 8/14) [31]. It was found to have a sensitivity of 97.5\% (95\% CI, 91.3-99.3\%), negative predictive value of 98.4\% (95\% CI, 94.4-99.6\%), and a negative likelihood ratio of 0.07 (95\% CI, 0.02-0.27). A systematic review with metaanalysis revealed that neutrophil-to-lymphocyte (NEU/LYMP) ratio could possibly be used for identification of AA and prediction of its severity (NAA or CAA) [23]. Binary logistic regression analysis showed that a NEU/LYMP ratio greater than 4.7 was an independent predictor of AA, with sensitivity of $88.89 \%$ (95\% CI 70.8-97.6\%), specificity of $90.91 \%$ (95\% CI, 58.7-99.8\%), and with a high accuracy (AUC) of 0.96 (95\% CI 0.84-1.0, $p<0.0001$ ). Additionally, NEU/LYMP ratio $>8.8$ was identified as independent predictor of CAA with sensitivity of $76.92 \%(95 \%$ CI, $46.2-95.0 \%)$ and specificity of $100 \%(95 \%$ CI, $75.3-100 \%)$ with AUC being 0.91 (95\% CI 0.73-0.99, $p<0.0001)$. Another prospective observational study has shown that it is very unlikely that patients with normal concentrations of inflammatory markers will have AA (negative predictive value reached 95\% when WBC count value was within normal range alone, and $100 \%$ when both WBC and CRP concentrations were normal) [32]. Normal inflammatory marker values are very unlikely in cases of AA, and laboratory tests may be appropriate to initially rule out the diagnosis of AA [25,33-35]. Therefore, when inflammatory markers' values are within normal ranges, a watchful waiting could be chosen, which in turn could reduce the excessive use of CT. In our study, we did not estimate optimal cut-off values for inflammatory indicators which would be reliable to confirm the diagnosis of AA. Furthermore, we did not analyse the accuracy of inflammatory markers in rejecting the diagnosis of AA. However, we noticed that patients in the No-AA group had a significantly lower WBC count and CRP concentration compared to the CAA group during the first 24 and $24-48 \mathrm{~h}$ after onset of the disease, and these results are similar to the findings of other studies, mentioned earlier.

According to the 2020 update of the WSES Jerusalem guidelines, the antibiotic-first strategy can be considered safe and effective in selected patients with uncomplicated acute appendicitis [3]. Based on this statement, our previously mentioned observation could theoretically suggest that patients with symptoms similar to AA, but with low WBC and CRP levels, could possibly have NAA or no AA at all, and, in that case, they could be carefully selected and treated conservatively without the need for excessive use of CT.

Changes in the concentrations of individual inflammatory indicators are not sufficiently accurate in suspecting or excluding the diagnosis of AA [25]. However, when combined with each other or with other clinical examinations, the accuracy of laboratory tests in diagnosing AA increases $[20,25,34]$. Combinations of inflammatory marker values with each other or with clinical symptoms and signs can effectively contribute to ruling out the diagnosis of $\mathrm{AA}$ and triaging patients who are suspected to have AA [6,31]. Many clinical scores that can be used in the diagnosis of AA are reported in the literature. Alvarado, Appendicitis Inflammatory Response (AIR), Adult Appendicitis Score (AAS), Raja Isteri Pengiran Anak Saleha Appendicitis (RIPASA), and many other AA diagnostic scores combine certain clinical signs and symptoms with inflammatory markers [6,36-38]. These scores are used in clinical practice, and some of the most studied and most often included in the international guidelines for AA are Alvarado, AIR, and ASS scores [3]. The Alvarado score is suitable for rejecting the diagnosis of AA when the cut-off point is less than 5 (sensitivity of $99 \%$ ) but not accurate enough to "rule-in" the diagnosis of AA [6]. The AIR score has been shown to be the best clinical predictor $(92 \%$ sensitivity and $63 \%$ specificity) of AA among other scores [39]. The 2020 update of the WSES Jerusalem guidelines recommends against using the Alvarado score to positively confirm the clinical suspicion of AA in adults, and to use the AIR score and AAS score as clinical predictors 
of AA [3]. Moreover, the addition of laboratory tests' results may increase the accuracy of imaging studies when AA is suspected-a retrospective cohort study demonstrated that the combination of ultrasound and WBC count with the polymorphonuclear leukocyte differential can considerably improve the predictive value of ultrasound in diagnosing AA in children (with positive predictive value reaching up to $96.8 \%$, and negative predictive value reaching up to $100 \%$ in certain cases) [40]. Our linear logistic regression model, which involved only inflammatory mediators and clinical characteristics, showed moderate diagnostic accuracy, with an AUC of 0.737 (0.671-0.802). We did not analyse how changes in inflammatory indicators could affect the accuracy of ultrasound in diagnosing AA, but this could be a useful topic for future research. However, we noticed that WBC count, NEU, and CRP were significantly higher in the CAA group than in the No-AA group during the first $48 \mathrm{~h}$ from the onset of the disease. For future research, it could be useful to examine whether these three inflammatory markers combined have greater diagnostic accuracy in suspecting AA than each alone.

In addition to classical inflammatory markers (such as leukocytes and CRP) used in the evaluation of diagnostics of AA, the literature indicates other new and innovative inflammatory markers which could be potentially used in diagnosing AA. Possible utilization of bilirubin, ischemia-modified albumin, interleukin-6, serum amyloid A, matrix metalloproteinase, myeloperoxidase, calprotectin, serum fibrinogen, and other laboratory markers in the diagnostics of AA were described in the literature [25,41-47]. However, the application of a significant proportion of these laboratory tests in clinical practice is limited because smaller medical institutions (which are not tertiary centers) do not have the technological capacity to identify these indicators. In addition, a significant proportion of these inflammatory markers are characterized by low to moderate sensitivity and specificity as well as middling prognostic accuracy in suspecting AA $[25,26]$. Two meta-analyses showed the high diagnostic accuracy of procalcitonin in suspecting CAA. Procalcitonin's positive likelihood ratio in diagnosing CAA reached 9.53 (sensitivity-62\%, specificity-94\%, AUC - 0.94) in one study [48], and the diagnostic odds ratio of procalcitonin in diagnosing CAA reached $76.7(2.1,272.9)$ in other research (sensitivity-89\%, specificity-90\%, AUC-0.96) [49]. In our study, for the evaluation of laboratory tests' dynamics, we used a classical panel of inflammatory markers (consisting of WBC count, NEU, LYMP, NEU/LYMP, and CRP). Based on the observations of these two meta-analyses, for future work it may be useful to include procalcitonin in the list of laboratory tests to be analysed.

This study demonstrated that increased concentrations of inflammatory markers are more characteristic in CAA patients than in No-AA patients during the first $48 \mathrm{~h}$ after onset of the disease. Furthermore, a combination of laboratory tests with clinical signs and symptoms has a mediocre diagnostic accuracy in suspecting AA.

\section{Conclusions}

To conclude, we found that elevated inflammatory markers are more likely to be present in cases of complicated acute appendicitis during first $48 \mathrm{~h}$ after onset of the disease than in other conditions when the appendix remains normal. Laboratory tests alone or in combination with other clinical examinations could be a useful diagnostic tool in suspecting acute appendicitis, however, more research is needed to elucidate the exact role of inflammatory markers in the diagnostics of acute appendicitis.

Author Contributions: Conception or design of the work-T.P., R.L.-L., A.A.K.; The acquisition of data for the work-R.L.-L., A.A.K., M.K., A.S.; Analysis and interpretation of data-all authors. Drafting the work critically for important intellectual content-A.A.K., R.L.-L., E.J., T.P. Revising the work for important intellectual content-all authors. Final approval of the version to be publishedall authors. Agreement to be accountable for all aspects of the work in ensuring that questions related to the accuracy or integrity of any part of the work are appropriately investigated and resolved-all authors. All authors have read and agreed to the published version of the manuscript.

Funding: No funding was received for this study. 
Institutional Review Board Statement: The study was conducted according to the guidelines of the Declaration of Helsinki, and approved by the Regional Ethics Committee of Vilnius Region Bioethics Committee (approval number 2019/3-1107-610).

Informed Consent Statement: All subjects signed an informed consent to participate in the study.

Data Availability Statement: Anonymized data are available from the senior author (TP) on reasonable request.

Conflicts of Interest: The authors declare no conflict of interest.

\section{References}

1. Wickramasinghe, D.P.; Xavier, C.; Samarasekera, D.N. The Worldwide Epidemiology of Acute Appendicitis: An Analysis of the Global Health Data Exchange Dataset. World J. Surg. 2021, 45, 1999-2008. [CrossRef]

2. Stewart, B.; Khanduri, P.; McCord, C.; Ohene-Yeboah, M.; Uranues, S.; Vega Rivera, F.; Mock, C. Global Disease Burden of Conditions Requiring Emergency Surgery. Br. J. Surg. 2014, 101, e9-e22. [CrossRef]

3. Di Saverio, S.; Podda, M.; De Simone, B.; Ceresoli, M.; Augustin, G.; Gori, A.; Boermeester, M.; Sartelli, M.; Coccolini, F.; Tarasconi, A.; et al. Diagnosis and Treatment of Acute Appendicitis: 2020 Update of the WSES Jerusalem Guidelines. World J. Emerg. Surg. 2020, 15, 27. [CrossRef]

4. Salminen, P.; Tuominen, R.; Paajanen, H.; Rautio, T.; Nordström, P.; Aarnio, M.; Rantanen, T.; Hurme, S.; Mecklin, J.-P.; Sand, J.; et al. Five-Year Follow-up of Antibiotic Therapy for Uncomplicated Acute Appendicitis in the APPAC Randomized Clinical Trial. JAMA 2018, 320, 1259-1265. [CrossRef]

5. Sallinen, V.; Akl, E.A.; You, J.J.; Agarwal, A.; Shoucair, S.; Vandvik, P.O.; Agoritsas, T.; Heels-Ansdell, D.; Guyatt, G.H.; Tikkinen, K.A.O. Meta-Analysis of Antibiotics versus Appendicectomy for Non-Perforated Acute Appendicitis. Br. J. Surg. 2016, 103, 656-667. [CrossRef] [PubMed]

6. Ohle, R.; O’Reilly, F.; O’Brien, K.K.; Fahey, T.; Dimitrov, B.D. The Alvarado Score for Predicting Acute Appendicitis: A Systematic Review. BMC Med. 2011, 9, 139. [CrossRef]

7. Kryzauskas, M.; Danys, D.; Poskus, T.; Mikalauskas, S.; Poskus, E.; Jotautas, V.; Beisa, V.; Strupas, K. Is Acute Appendicitis Still Misdiagnosed? Open Med. 2016, 11, 231-236. [CrossRef] [PubMed]

8. Ahmed, H.O.; Muhammed, A.M. Alternative Diagnosis for Pain in Patients Who Underwent Appendectomies for Normal Appendices and the Incidence of Negative Appendectomies. Ann. Coll. Med. Mosul. 2011, 37, 80-86. [CrossRef]

9. Liese, J.; Halbinger, T.M.; Ulrich, F.; Bechstein, W.O.; Strey, C.W. Appendicitis-The Balance between Cost Effectiveness and Safety Remains Challenging. Langenbecks Arch. Surg. 2014, 399, 493-501. [CrossRef] [PubMed]

10. Alhamdani, Y.F.; Rizk, H.A.; Algethami, M.R.; Algarawi, A.M.; Albadawi, R.H.; Faqih, S.N.; Ahmed, E.H.; Abukammas, O.J. Negative Appendectomy Rate and Risk Factors That Influence Improper Diagnosis at King Abdulaziz University Hospital. Mater. Socio-Med. 2018, 30, 215-220. [CrossRef] [PubMed]

11. Lukenaite, B.; Luksaite-Lukste, R.; Mikalauskas, S.; Samuilis, A.; Strupas, K.; Poškus, T. Magnetic Resonance Imaging Reduces the Rate of Unnecessary Operations in Pregnant Patients with Suspected Acute Appendicitis: A Retrospective Study. Ann. Surg. Treat. Res. 2021, 100, 40-46. [CrossRef] [PubMed]

12. Hendriks, I.G.J.; Langen, R.M.R.; Janssen, L.; Verrijth-Wilms, I.M.H.A.; Wouda, S.; Janzing, H.M.J. Does the Use of Diagnostic Imaging Reduce the Rate of Negative Appendectomy? Acta Chir. Belg. 2015, 115, 393-396. [CrossRef]

13. Coursey, C.A.; Nelson, R.C.; Patel, M.B.; Cochran, C.; Dodd, L.G.; DeLong, D.M.; Beam, C.A.; Vaslef, S. Making the Diagnosis of Acute Appendicitis: Do More Preoperative CT Scans Mean Fewer Negative Appendectomies? A 10-Year Study. Radiology 2010, 254, 460-468. [CrossRef]

14. Fu, J.; Zhou, X.; Chen, L.; Lu, S. Abdominal Ultrasound and Its Diagnostic Accuracy in Diagnosing Acute Appendicitis: A Meta-Analysis. Front. Surg. 2021, 8, 707160. [CrossRef] [PubMed]

15. Kim, D.W.; Suh, C.H.; Yoon, H.M.; Kim, J.R.; Jung, A.Y.; Lee, J.S.; Cho, Y.A. Visibility of Normal Appendix on CT, MRI, and Sonography: A Systematic Review and Meta-Analysis. Am. J. Roentgenol. 2018, 211, W140-W150. [CrossRef]

16. Rud, B.; Vejborg, T.S.; Rappeport, E.D.; Reitsma, J.B.; Wille-Jørgensen, P. Computed Tomography for Diagnosis of Acute Appendicitis in Adults. Cochrane Database Syst. Rev. 2019, 2019, CD009977. [CrossRef]

17. Eng, K.A.; Abadeh, A.; Ligocki, C.; Lee, Y.K.; Moineddin, R.; Adams-Webber, T.; Schuh, S.; Doria, A.S. Acute Appendicitis: A Meta-Analysis of the Diagnostic Accuracy of US, CT, and MRI as Second-Line Imaging Tests after an Initial US. Radiology 2018, 288, 717-727. [CrossRef] [PubMed]

18. Smith-Bindman, R. Radiation dose associated with common computed tomography examinations and the associated lifetime attributable risk of cancer. Arch. Intern. Med. 2009, 169, 2078. [CrossRef]

19. Luksaite-Lukste, R.; Kliokyte, R.; Samuilis, A.; Jasiunas, E.; Luksta, M.; Strupas, K.; Poskus, T. Conditional CT Strategy-An Effective Tool to Reduce Negative Appendectomy Rate and the Overuse of the CT. J. Clin. Med. 2021, 10, 2456. [CrossRef] [PubMed]

20. Andersson, R.E.B. Meta-Analysis of the Clinical and Laboratory Diagnosis of Appendicitis. Br. J. Surg. 2004, 91, 28-37. [CrossRef] 
21. Vaughan-Shaw, P.; Rees, J.; Bell, E.; Hamdan, M.; Platt, T. Normal Inflammatory Markers in Appendicitis: Evidence from Two Independent Cohort Studies. JRSM Short Rep. 2011, 2, 1-8. [CrossRef]

22. Er, S.; Çomçalı, B.; Soykurt, A.; Cavit Yüksel, B.; Tez, M. Diagnosis of Appendicitis in Patients with a Normal White Blood Cell Count; A Cross-Sectional Study. Bull. Emerg. Trauma 2018, 6, 128-132. [CrossRef]

23. Hajibandeh, S.; Hajibandeh, S.; Hobbs, N.; Mansour, M. Neutrophil-to-Lymphocyte Ratio Predicts Acute Appendicitis and Distinguishes between Complicated and Uncomplicated Appendicitis: A Systematic Review and Meta-Analysis. Am. J. Surg. 2020, 219, 154-163. [CrossRef] [PubMed]

24. Shogilev, D.J.; Duus, N.; Odom, S.R.; Shapiro, N.I. Diagnosing Appendicitis: Evidence-Based Review of the Diagnostic Approach in 2014. West. J. Emerg. Med. 2014, 15, 859-871. [CrossRef]

25. Kabir, S.A.; Kabir, S.I.; Sun, R.; Jafferbhoy, S.; Karim, A. How to Diagnose an Acutely Inflamed Appendix; a Systematic Review of the Latest Evidence. Int. J. Surg. 2017, 40, 155-162. [CrossRef]

26. Acharya, A.; Markar, S.R.; Ni, M.; Hanna, G.B. Biomarkers of Acute Appendicitis: Systematic Review and Cost-Benefit Trade-off Analysis. Surg. Endosc. 2017, 31, 1022-1031. [CrossRef] [PubMed]

27. Poortman, P.; Oostvogel, H.J.M.; Bosma, E.; Lohle, P.N.M.; Cuesta, M.A.; Klerk, E.S.M.d.L.; Hamming, J.F. Improving Diagnosis of Acute Appendicitis: Results of a Diagnostic Pathway with Standard Use of Ultrasonography Followed by Selective Use of CT. J. Am. Coll. Surg. 2009, 208, 434-441. [CrossRef] [PubMed]

28. Krishnamoorthi, R.; Ramarajan, N.; Wang, N.E.; Newman, B.; Rubesova, E.; Mueller, C.M.; Barth, R.A. Effectiveness of a Staged US and CT Protocol for the Diagnosis of Pediatric Appendicitis: Reducing Radiation Exposure in the Age of ALARA. Radiology 2011, 259, 231-239. [CrossRef]

29. Atema, J.J.; Gans, S.L.; Van Randen, A.; Laméris, W.; van Es, H.W.; van Heesewijk, J.P.M.; van Ramshorst, B.; Bouma, W.H.; ten Hove, W.; van Keulen, E.M.; et al. Comparison of Imaging Strategies with Conditional versus Immediate Contrast-Enhanced Computed Tomography in Patients with Clinical Suspicion of Acute Appendicitis. Eur. Radiol. 2015, 25, 2445-2452. [CrossRef]

30. Toorenvliet, B.R.; Wiersma, F.; Bakker, R.F.R.; Merkus, J.W.S.; Breslau, P.J.; Hamming, J.F. Routine Ultrasound and Limited Computed Tomography for the Diagnosis of Acute Appendicitis. World J. Surg. 2010, 34, 2278-2285. [CrossRef]

31. Huckins, D.S.; Copeland, K.; Self, W.; Vance, C.; Hendry, P.; Borg, K.; Gogain, J. Diagnostic Performance of a Biomarker Panel as a Negative Predictor for Acute Appendicitis in Adult ED Patients with Abdominal Pain. Am. J. Emerg. Med. 2017, 35, 418-424. [CrossRef] [PubMed]

32. Sengupta, A.; Bax, G.; Paterson-Brown, S. White Cell Count and C-Reactive Protein Measurement in Patients with Possible Appendicitis. Ann. R. Coll. Surg. Engl. 2009, 91, 113-115. [CrossRef]

33. Khan, M.N.; Davie, E.; Irshad, K. The Role of White Cell Count and C-Reactive Protein in the Diagnosis of Acute Appendicitis. J. Ayub Med. Coll. Abbottabad JAMC 2004, 16, 17-19. [PubMed]

34. Soldo, I.; Radisic Biljak, V.; Bakula, B.; Bakula, M.; Simundic, A.-M. The Diagnostic Accuracy of Clinical and Laboratory Parameters in the Diagnosis of Acute Appendicitis in the Adult Emergency Department Population-A Case Control Pilot Study. Biochem. Medica 2018, 28, 030712. [CrossRef]

35. Yang, H.-R.; Wang, Y.-C.; Chung, P.-K.; Chen, W.-K.; Jeng, L.-B.; Chen, R.-J. Laboratory Tests in Patients with Acute Appendicitis. ANZ J. Surg. 2006, 76, 71-74. [CrossRef]

36. Von-Mühlen, B.; Franzon, O.; Beduschi, M.G.; Kruel, N.; Lupselo, D. AIR SCORE ASSESSMENT FOR ACUTE APPENDICITIS. Arq. Bras. Cir. Dig. ABCD Braz. Arch. Dig. Surg. 2015, 28, 171-173. [CrossRef]

37. Sammalkorpi, H.E.; Mentula, P.; Savolainen, H.; Leppäniemi, A. The Introduction of Adult Appendicitis Score Reduced Negative Appendectomy Rate. Scand. J. Surg. 2017, 106, 196-201. [CrossRef]

38. Chong, C.F.; Adi, M.I.W.; Thien, A.; Suyoi, A.; Mackie, A.J.; Tin, A.S.; Tripathi, S.; Jaman, N.H.; Tan, K.K.; Kok, K.Y.; et al. Development of the RIPASA Score: A New Appendicitis Scoring System for the Diagnosis of Acute Appendicitis. Singapore Med. J. 2010, 51, 220-225.

39. Kularatna, M.; Lauti, M.; Haran, C.; MacFater, W.; Sheikh, L.; Huang, Y.; McCall, J.; MacCormick, A.D. Clinical Prediction Rules for Appendicitis in Adults: Which Is Best? World J. Surg. 2017, 41, 1769-1781. [CrossRef] [PubMed]

40. Anandalwar, S.P.; Callahan, M.J.; Bachur, R.G.; Feng, C.; Sidhwa, F.; Karki, M.; Taylor, G.A.; Rangel, S.J. Use of White Blood Cell Count and Polymorphonuclear Leukocyte Differential to Improve the Predictive Value of Ultrasound for Suspected Appendicitis in Children. J. Am. Coll. Surg. 2015, 220, 1010-1017. [CrossRef]

41. Burcharth, J.; Pommergaard, H.C.; Rosenberg, J.; Gögenur, I. Hyperbilirubinemia as a Predictor for Appendiceal Perforation: A Systematic Review. Scand. J. Surg. 2013, 102, 55-60. [CrossRef]

42. Kıllı̧, M.Ö.; Güldoğan, C.E.; Balamir, İ.; Tez, M. Ischemia-Modified Albumin as a Predictor of the Severity of Acute Appendicitis. Am. J. Emerg. Med. 2017, 35, 92-95. [CrossRef]

43. Andersson, M.; Rubér, M.; Ekerfelt, C.; Hallgren, H.B.; Olaison, G.; Andersson, R.E. Can New Inflammatory Markers Improve the Diagnosis of Acute Appendicitis? World J. Surg. 2014, 38, 2777-2783. [CrossRef]

44. Paajanen, H.; Mansikka, A.; Laato, M.; Ristamäki, R.; Pulkki, K.; Kostiainen, S. Novel Serum Inflammatory Markers in Acute Appendicitis. Scand. J. Clin. Lab. Investig. 2002, 62, 579-584. [CrossRef] [PubMed]

45. Naqvi, S.A.; Thompson, G.C.; Joffe, A.R.; Blackwood, J.; Martin, D.-A.; Brindle, M.; Barkema, H.W.; Jenne, C.N. Cytokines and Chemokines in Pediatric Appendicitis: A Multiplex Analysis of Inflammatory Protein Mediators. Mediat. Inflamm. 2019, 2019, e2359681. [CrossRef] [PubMed] 
46. Nyuwi, K.T.; Singh, C.G.; Khumukcham, S.; Rangaswamy, R.; Ezung, Y.S.; Chittvolu, S.R.; Sharma, A.B.; Singh, H.M. The Role of Serum Fibrinogen Level in the Diagnosis of Acute Appendicitis. J. Clin. Diagn. Res. 2017, 11, PC13-PC15. [CrossRef]

47. Benito, J.; Acedo, Y.; Medrano, L.; Barcena, E.; Garay, R.P.; Arri, E.A. Usefulness of New and Traditional Serum Biomarkers in Children with Suspected Appendicitis. Am. J. Emerg. Med. 2016, 34, 871-876. [CrossRef]

48. Yu, C.-W.; Juan, L.-I.; Wu, M.-H.; Shen, C.-J.; Wu, J.-Y.; Lee, C.-C. Systematic Review and Meta-Analysis of the Diagnostic Accuracy of Procalcitonin, C-Reactive Protein and White Blood Cell Count for Suspected Acute Appendicitis. Br. J. Surg. 2013, 100, 322-329. [CrossRef]

49. Cui, W.; Liu, H.; Ni, H.; Qin, X.; Zhu, L. Diagnostic Accuracy of Procalcitonin for Overall and Complicated Acute Appendicitis in Children: A Meta-Analysis. Ital. J. Pediatr. 2019, 45, 78. [CrossRef] [PubMed] 